\title{
ADEQUACY EVALUATION OF THE SYNTHESIS OF MATHEMATICAL MODELS FOR ONE CLASS OF LINEAR DYNAMIC SYSTEMS WITH PARAMETERS, VARIABLE IN TIME AND IN SPACE
}

\author{
Borys Mokin $^{1}$, Oleksandr Mokin ${ }^{2}$, Oleksandr Kryvonis ${ }^{3}$ \\ ${ }^{1}$ Department of electromechanical systems automation in industry and transport, Department of systems analysis and information tech- \\ nologies, Vinnytsia National Technical University, Vinnytsia, Ukraine \\ borys.mokin@gmail.com \\ ORCID: http://orcid.org/0000-0002-5906-6122 \\ ${ }^{2}$ Department of systems analysis and information technologies, Vinnytsia National Technical University, Vinnytsia, Ukraine \\ abmokin@gmail.com \\ ORCID: http://orcid.org/0000-0002-9277-3312 \\ ${ }^{3}$ Department of electromechanical systems automation in industry and transport, Vinnytsia National Technical University, Vinnytsia, Ukraine \\ kryvonis.ol@gmail.com \\ ORCID: http://orcid.org/0000-0002-3734-1197
}

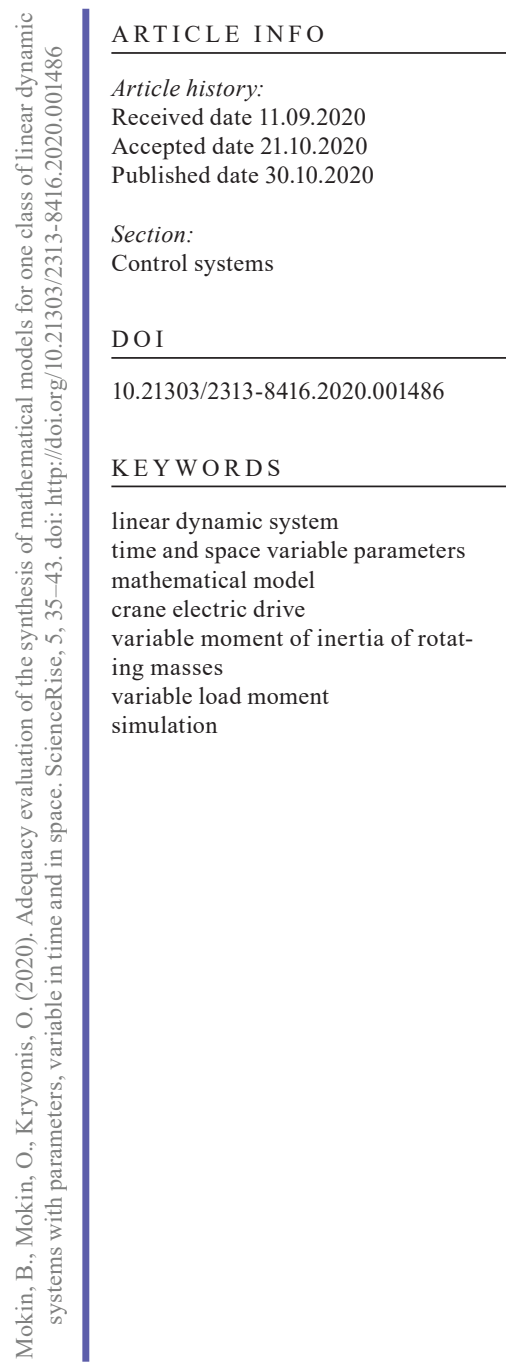

\section{ABSTRACT}

The object of research: the authors of this work have synthesized in previous publications a mathematical model of one class of linear dynamic systems with variable parameters in time and space, which includes the system for lifting and lowering a load with a crane in the case of taking into account the influence of longitudinal vibrations that arise in the cable of the lifting mechanism, and shift in time of the moment of inertia of the rotating masses reduced to the motor shaft.

Investigated problem: simulation models are synthesized in the Simulink graphical software environment of the MATLAB application package to assess the adequacy of the specified mathematical model. A calculation was carried out using the passport data and characteristics of all components of the crane structure to find the numerical values of the parameters of simulation models, including the electric motor, cable and gearbox.

The main scientific results: the results of modeling the dynamics of the electric drive system during acceleration, deceleration, the prevailing velocity are given. By comparing the results obtained on the simulation model with the results of experimental studies of the same class of dynamical systems carried out by other authors, the adequacy of the mathematical models synthesized by the authors of this work is proved. It is proved that the use of the classical equation of the dynamics of the electric drive system, which contains a constant moment of inertia and a constant moment of load, leads to errors in the estimates of the processes accompanying the lifting and lowering of loads by cranes. And this, in turn, does not allow predicting the behavior of the system in various operating modes with sufficient accuracy.

The area of practical use of the research results: enterprises of the machine-building industry, specializing in the production, modernization of lifting equipment.

Innovative technological product: a simulation model of a crane mechanism, which makes it possible to take into account the influence of longitudinal vibrations that arise in the cable of the hoisting mechanism, and the shift in time of the moment of inertia of the rotating masses reduced to the motor shaft.

Scope of application of the innovative technological product: design and development of control systems for electric drives of lifting equipment.

(C) The Author(s) 2020. This is an open access article under the CC BY license http://creativecommons.org/licenses/by/4.0).

\section{Introduction}

\section{1. The object of research}

The authors of this work have synthesized in previous publications a mathematical model of one class of linear dynamic systems with variable parameters in time and space, which includes the system for lifting and lowering a load by a crane in the case of taking into account the influence of longitudinal vibrations that occur in the cable of the lifting mechanism, and shifts in time the moment of inertia of the rotating masses reduced to the motor shaft. 


\section{2. Problem description}

Cranes and mine splinters, which, using ropes and electric traction drives, lift and lower loads, represent a wide class of linear dynamic systems with parameters that are variable in time and space (LDSPVTS).

Scientists have been studying the dynamics of this class of systems for a long time, and among the publications carried out 50 and more years ago, it is worth noting the publications of S. Kazak. In 1968, M. Gokhberg and in 1969, M. Komarova, in which the authors analyze the transient processes that occur in the elements of such systems, based on the representation of their structures in the form of two-mass dynamic objects with lumped parameters. In a later work, N. Lobov 1987, which is also devoted to research in this direction, retains the same approach as that of its predecessors, but with greater detail.

And even even in the studies carried out at the beginning of this century and published in [1-3], there is a tendency to use constant parameters in models, and to achieve detailed processes only by increasing the number of interconnected masses with lumped parameters.

And only in works [4-6] their authors are already trying to take into account the distribution of the parameters of these systems in space, emphasizing that taking into account the distributed parameters does not significantly add to the accuracy of determining the transient processes, since due to the components due to the distribution of parameters, they failed to add more than $4 \%$.

In our opinion, the most detailed work devoted to both the analysis of studies of the dynamics of a certain class of dynamical systems, obtained by those authors already mentioned, and devoted to obtaining their own results of studying this class of systems, is [7], in which, however, there are two disappointing conclusions that are worth quoting. So in one of the conclusions to section 1 of work [7] it is indicated that: "For research, it is acceptable to use dynamic models with lumped masses." And the second conclusion, as a result of the analysis of publications known to the authors of [7], is set out in Chapter 2, and it has the form of an assertion that: "To study the dynamics of cargo movement by a bridge crane, two, three, four, seven and eight mass dynamic structures and their mathematical models, however, there are no recommendations for their use".

But pointing out the shortcomings of the mathematical models synthesized by other researchers, the authors of [7], starting the synthesis of their own models, in Section 3 indicate that they create these models, proceeding from the fact that the radius of the rope winding drum is a constant value and the rotating masses on throughout the entire movement of the load remain constant, and therefore the moment of inertia of the rotating masses reduced to the traction motor shaft remains constant, that is, proceeding from the fact that the differential equation is valid for the traction electric drive system

$$
J \frac{\mathrm{d} \omega}{\mathrm{d} t}=M_{e d}-M_{w}=\Delta M,
$$

where $M_{e d}$ - the traction moment created by the electric motor and predetermines the rotation of its shaft with angular velocity $\omega ; M_{w}$ - the moment of the load created by the load, which is raised or lowered, $\Delta M$ - the dynamic moment of the moving system, and $J$ - the reduced moment of inertia of the rotating masses of the electric drive system, which is assumed constant by all the researchers, whose work were mentioned.

When winding the traction cable onto the drum and unwinding from the drum, the real winding radius changes and the length of the cable between the drum and the load changes (and significantly).

Therefore, the reduced moment of inertia of the rotating masses of the electric drive system also changes in the process of lifting and lowering the load, that is, it is a function of time $J(t)$. Therefore, as shown in our work [8], to analyze the transient processes in the electric drive of the crane, one should use the differential equation (1), and the differential equation

$$
\frac{\mathrm{d}(J \omega)}{\mathrm{d} t}=J(t) \frac{\mathrm{d} \omega}{\mathrm{d} t}+\omega(t) \frac{\mathrm{d} J}{\mathrm{~d} t}=M_{e d}-M_{w}(t)=\Delta M(t)
$$

with parameters: 


$$
\begin{gathered}
\left\{\begin{array}{l}
M\left(t_{1}\right)=M_{P}\left(1+k_{1} \omega-k_{2} \omega^{2}\right), \\
M\left(t_{2}\right)=M_{P}\left(1+k_{1} \omega_{y}^{*}-k_{2}\left(\omega_{y}^{*}\right)^{2}\right), \\
M\left(t_{3}\right)=-M_{P}\left(1+k_{1} \omega-k_{2} \omega^{2}\right),
\end{array}\right. \\
\left\{\begin{array}{l}
M_{w}\left(t_{1}\right)=M_{w 0}-\alpha_{1}^{*} t-\frac{\alpha_{2}^{*}}{2} t^{2}, \\
M_{w}\left(t_{2}\right)=M_{w}\left(t_{1}\right)-\alpha_{1}^{*}\left(t-t_{1}\right), \\
M_{w}\left(t_{3}\right)=M_{w}\left(t_{2}\right)-\alpha_{1}^{*}\left(t-t_{2}\right)-\frac{\alpha_{2}^{*}}{2}\left(t-t_{2}\right)^{2}, \\
J\left(t_{1}\right)=J_{0}^{*}-c_{1}^{*} t_{1}+\frac{c_{2}^{*}}{2} t_{1}^{2}, \\
J\left(t_{2}\right)=J\left(t_{1}\right)-c_{1}^{*} t_{21}+\frac{c_{2}^{*}}{2} t_{21}^{2}, \\
J\left(t_{3}\right)=J\left(t_{2}\right)-c_{1}^{*} t_{32}+\frac{c_{2}^{*}}{2} t_{32}^{2}=J_{0}^{* *},
\end{array}\right.
\end{gathered}
$$

where $t_{1}, t_{2}, t_{3}$ - in accordance with the moment when the angular velocity of the electric motor reaches a constant value after starting, the moment of completion of motion with a constant angular velocity and the moment of stopping the motion.

And in order to be able to assess the longitudinal vibrations arising in the cables, in our works $[9,10]$, it is proposed to integrate the models

$$
\begin{aligned}
& \frac{\partial^{2} v(x, t)}{\partial x^{2}}-n m \frac{\partial^{2} v(x, t)}{\partial t^{2}}=0, \\
& \frac{\partial^{2} F(x, t)}{\partial x^{2}}-n m \frac{\partial^{2} F(x, t)}{\partial t^{2}}=0,
\end{aligned}
$$

in which $v(x, t), F(x, t)$ - respectively, the linear velocity of the cable with specific mass $\left(\frac{\mathrm{kg}}{\mathrm{m}^{3}}\right)$ and compliance $\left(\frac{\mathrm{m} \cdot \mathrm{c}^{2}}{\mathrm{~kg}}\right)$ and the force that takes place in its section at a distance $x$ from the origin of the spatial coordinate along the cable at the moment of time $t$. After all the necessary transformations, complementing models (2), (3) with models (4), let's obtain a solution to differential equation (2) in the form

$$
\omega_{i}=\omega_{y}^{*}-\frac{\left(b_{\omega}^{2}-\Delta_{\omega}^{(i)}\right)\left(e^{\sqrt{-\frac{4 \Delta_{\omega}^{(i)}}{\Delta_{t}}} \operatorname{arctg} \frac{2 a_{t} \sqrt{\Delta_{t}}\left(t_{i}-t_{2}\right)}{\Delta_{t}+b_{t}^{2}+2 a_{t} b_{t}\left(t_{i}-t_{2}\right)}}-1\right)}{2 a_{\omega}\left(b_{\omega}\left(1-e^{\sqrt{-\frac{4 \Delta_{\omega}^{(i)}}{\Delta_{t}}} \operatorname{arctg} \frac{2 a_{t} \sqrt{\Delta_{t}\left(t_{i}-t_{2}\right)}}{\Delta_{t}+b_{t}^{2}+2 a_{t} b_{t}\left(t_{i}-t_{2}\right)}}\right)+\sqrt{-\Delta_{\omega}^{(i)}}\left(1+e^{\sqrt{-\frac{\Delta_{\omega}^{(i)}}{\Delta_{t}}} \operatorname{arctg} \frac{2 a_{t} \sqrt{\Delta_{t}\left(t_{i}-t_{2}\right)}}{\Delta_{t}+b_{t}^{2}+2 a_{t} b_{t}\left(t_{i}-t_{2}\right)}}\right)\right.},
$$

where:

$$
\left\{\begin{array}{l}
a_{t}=\frac{c_{2}^{*}}{2} \\
b_{t}=-c_{1}^{*} \\
c_{t}=J_{0}^{*} \\
\Delta_{t}=4 a_{t} c_{t}-b_{t}^{2}=2 c_{2^{*}}^{*} J_{0}^{*}-\left(c_{1}^{*}\right)^{2}
\end{array}\right.
$$




$$
\left\{\begin{array}{l}
a_{\omega}=-M_{P} k_{2}, \\
b_{\omega}=M_{P} k_{1}, \\
c_{\omega}^{(i)}=M_{P}-M_{w}\left(t_{1}, t_{i}\right), \\
\Delta_{\omega}^{(i)}=4 a_{\omega} c_{\omega}^{(i)}-b_{\omega}^{2}=-4 M_{P} k_{2}\left(M_{P}-M_{w}\left(t_{1}, t_{i}\right)\right)-\left(M_{P} k_{1}\right)^{2} .
\end{array}\right.
$$

\section{3. Proposed way to solve the problem}

All the above mathematical models, taken from our previous publications, in this work of ours serve as the initial prerequisites for the synthesis of a simulation model of the processes taking place in the crane electric drive system, which have chosen as a typical dynamic object with parameters that change both in time and in space. And the simulation model itself will be used to check the previously obtained theoretical results for adequacy by means of their computer simulation using the real parameters of a particular crane and its electric drive system.

\section{Materials and methods}

The synthesis of a simulation model for modeling processes in the electric drive system of a crane, as an object from the class of dynamic ones with parameters variable in time and space, is carried out using the example of a crane installation with an asynchronous electric drive, which implements the process of lifting a load with a mass $m_{w}=400(\mathrm{~kg})$ to a height $h=10(\mathrm{~m})$. Others, necessary parameters of the crane installation let's choose with an asynchronous electric drive have the following values: the diameter of the cable $D_{T}=0.05(\mathrm{~m})$ to which the load is suspended, the mass of its running meter is equal $m_{M T}=5(\mathrm{~kg})$, the diameter of the coil on which the cable is wound when the load is lifted $D_{K}=0.2(\mathrm{~m})$, the mass of the coil is equal $m_{K}=15(\mathrm{~kg})$, the gear ratio of the gearbox, by which the traction force from the electric motor is transmitted to the cable coil is equal to $z=24$, the distance between the gearbox axes, one of which is connected to the traction motor shaft, and the second to the coil on which the cable is wound, to which the load is suspended $l=0.5(\mathrm{~m})$, the number of parallel axes in the gearbox $k=5$, the distance between the axles $l_{b a}=0.2(\mathrm{~m})$, the radius of the larger gear on the axle is equal $r_{b g}=0.12(\mathrm{~m})$, the mass of the larger gear on the axle is equal $m_{b g}=20(\mathrm{~kg})$, the radius of the smaller gear on the axle is equal $r_{s g}=0.08(\mathrm{~m})$, the mass of the smaller gear on the axle is equal $m_{s g}=11(\mathrm{~kg})$, and the passport characteristics of the asynchronous traction motor are: nominal moment $M_{N}=80(N \cdot m)$, moment of inertia $J^{*}=1.2(\mathrm{~N} \cdot \mathrm{m})$, synchronous angular velocity of rotation of the rotor $\omega_{c}=$ ùùù $\left(\right.$ ) efficiency $\eta_{N}=0.86$, rated slip $s_{N}=0.057$, critical slip $s_{k r}=0.251$, starting torque $M_{P}=q_{P} M_{N}$, maximum torque $M_{\max }=q_{\max } M_{N}$, where depending on the type of electric motor $q_{P} \in[1.1-2], q_{\max } \in[1.5-2,5]$.

Let's note that all quantities are set in the same SI system of units.

Listing of calculating the parameters of the mathematical model (2)-(7) in the PE Mathcad for a certain class of dynamic objects with parameters that are variable in time and space is shown in Fig. 1. And synthesized in the Matlab Simulink software environment using the numerical values of these parameters, the simulation model of the dynamic moment of the system, which sets the right side in the mathematical model (2), is shown in Fig. 2.

$$
\begin{array}{lll}
c_{1 x}:=\frac{\alpha_{1^{*}} \cdot t_{12}}{\omega_{y^{*}}}=0.032 \frac{\mathrm{kg} \cdot \mathrm{m}^{2}}{\mathrm{~s}} & a_{t}:=\frac{c_{2^{*}}}{2}=0.005 \mathrm{~J} \\
c_{2^{*}}:=\frac{2\left(J_{0^{* *}}-J_{0^{*}}-c_{1 x}\left(t_{1}+t_{12}+t_{23}\right)\right)}{t_{1}^{2}+t_{12}^{2}+t_{23}^{2}-2 \cdot t_{12}\left(t_{1}+t_{12}+t_{23}\right)}=0.009 \mathrm{~J} & b_{t}:=-c_{1^{*}}=-0.016 \frac{\mathrm{kg} \cdot \mathrm{m}^{2}}{\mathrm{~s}} \\
c_{t}:=J_{0^{*}}=0.177 \mathrm{~kg} \cdot \mathrm{m}^{2} \\
J_{0^{*}}:=J_{*}+\frac{1}{z_{i}^{2}} \cdot J_{i}+\left(m_{\omega}+m_{M T} \cdot h_{*}\right) \cdot \frac{\frac{D_{K}^{2}}{2^{2}}}{z^{2}}=0.177 \mathrm{~kg} \cdot \mathrm{m}^{2} a_{\omega}: c_{t}-b_{t}^{2}=0.003 \frac{\mathrm{kg}^{2} \cdot \mathrm{m}^{4}}{\mathrm{~s}^{2}} \\
b_{\omega}:=M_{P} \cdot k_{2}=-0.8 \mathrm{~J}
\end{array}
$$

Fig. 1. Listing of the calculation of the parameters of the mathematical model of the electric drive system of the crane for the simulation model of the processes of lifting loads with this crane and their lowering 


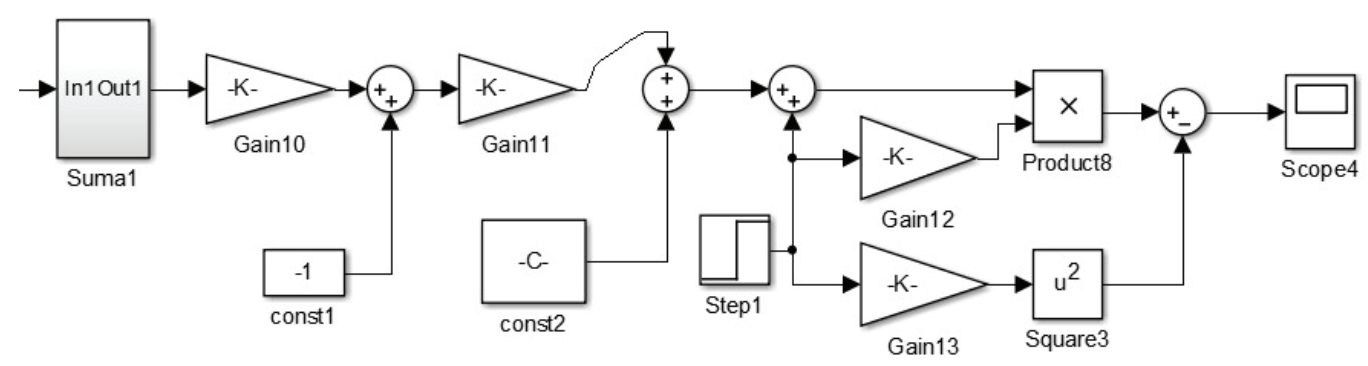

Fig. 2. Simulation model of the dynamic moment on the traction motor shaft of a crane electric drive system

The result of modeling the dynamic moment using the one shown in Fig. 2 of the simulation model is shown in Fig. 6 in the next section of this article devoted to the analysis of the entire set of results obtained.

Fig. 3-5 shows the simulation model synthesized by authors, with the help of which the operation of the system is simulated according to a typical tachogram for crane mechanisms, given in [8].

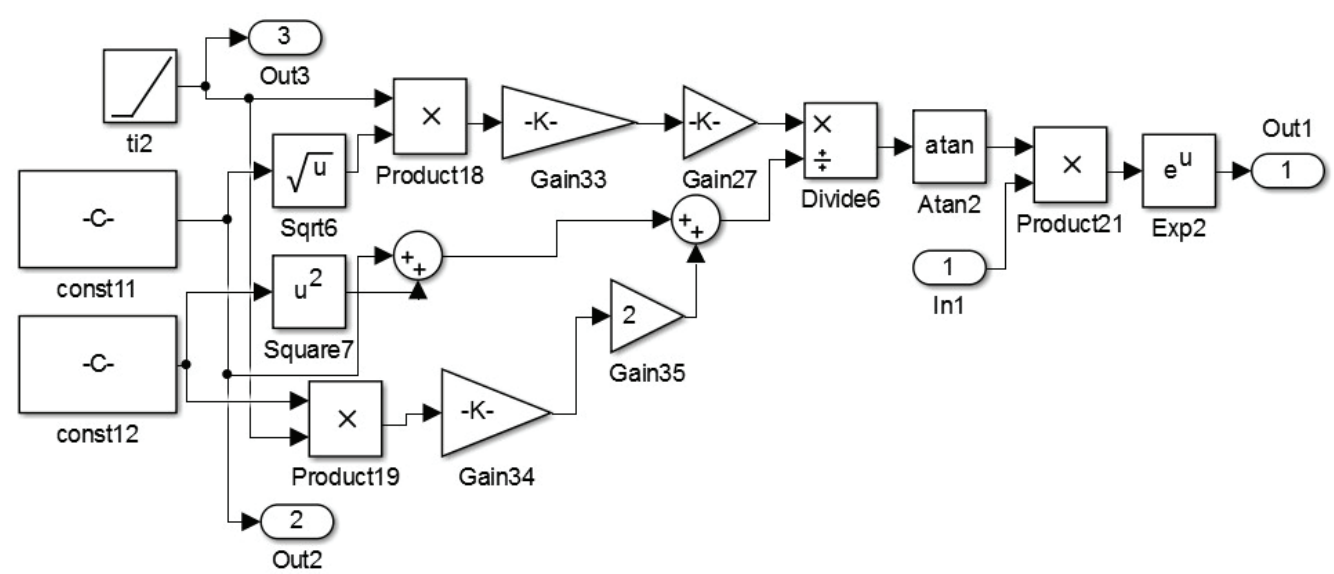

Fig. 3. The first part of the simulation model in the "Exp2" block of the electric drive system of the crane, taking into account the longitudinal vibrations of the load during its movement

To simulate a full cycle of lifting a load by a crane, it was taken into account that the equation of dynamics (2) for the period of motion of an electric drive with a steady angular velocity, as shown in our works $[9,10]$, takes the form:

$$
\left(c_{1}+c_{2}\left(t-t_{1}\right)\right) \omega_{\dot{o}}^{*}=\alpha_{1}\left(t-t_{1}\right)+R\left(\frac{G_{w}+G_{T}\left(a t_{1}, t_{1}\right)}{g}\right) g_{1 l}\left(\frac{2}{\pi} \sum_{k=0}^{5} \frac{1}{2 k+1}\left[\sin \frac{(2 k+1) \pi a t}{l}\right]\right) .
$$

And for the period of braking of the system during lifting, the equation for changing the load moment takes the form:

$$
-M_{w}\left(t_{2}, t\right)=R\left(\frac{G_{w}+G_{T}\left(a t_{2}, t_{2}\right)}{g}\right) g_{1 l}\left(-1+\frac{2}{\pi} \sum_{k=0}^{5} \frac{1}{2 k+1}\left[\sin \frac{(2 k+1) \pi a t}{l}\right]\right)+\alpha_{1}\left(t_{2}-t_{1}\right) .
$$

It is quite obvious that for the numerical determination of all coefficients in mathematical models, from model (2) to model (9), let's use the listing of parameters shown in Fig. 2.

The results of modeling dynamic processes using the one shown in Fig. 3-5 of the simulation model are also presented in the next section of this article, devoted to the analysis of the entire set of results obtained, in Fig. 7, 8. 


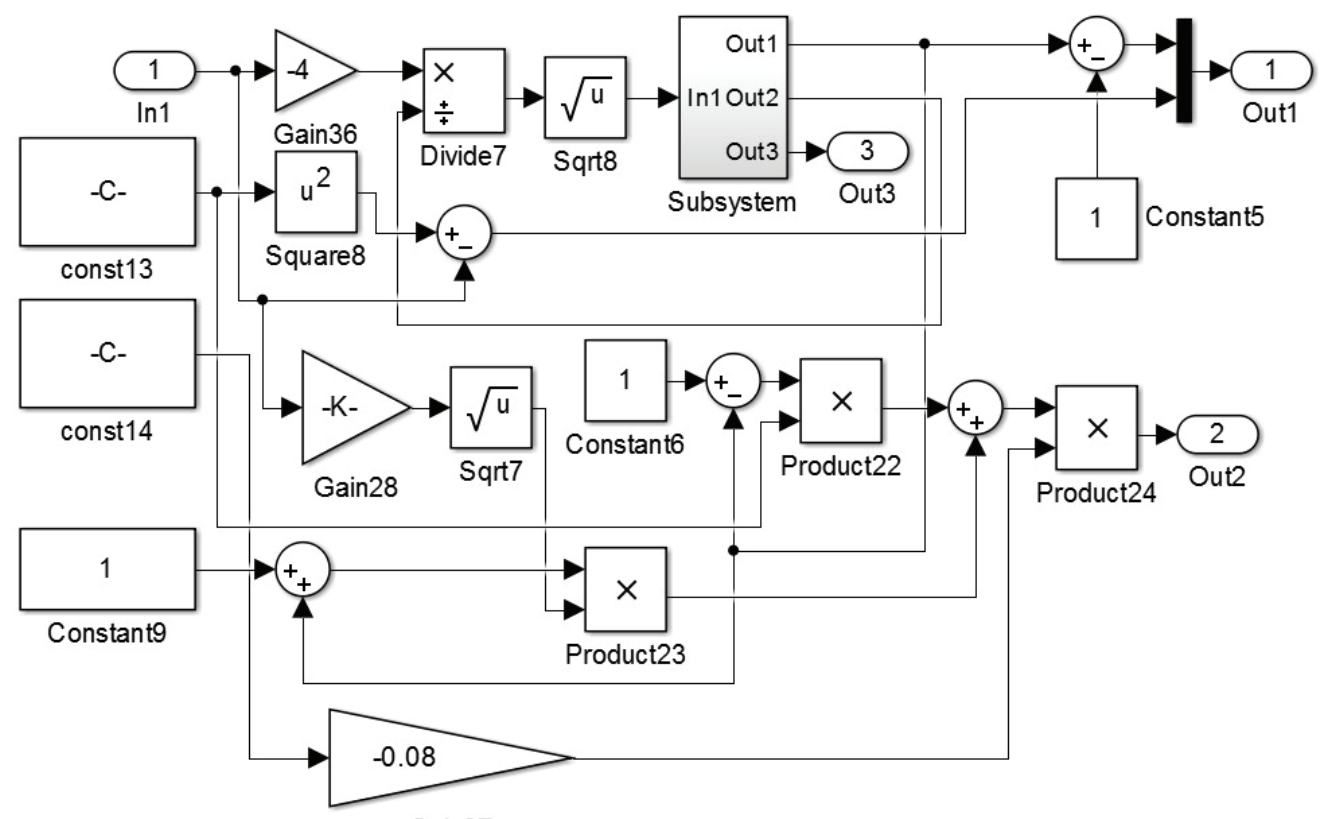

Gain37

Fig. 4. The second part of the simulation model into the "Mux" block of the electric drive system of the crane taking into account the longitudinal vibrations of the load during its movement

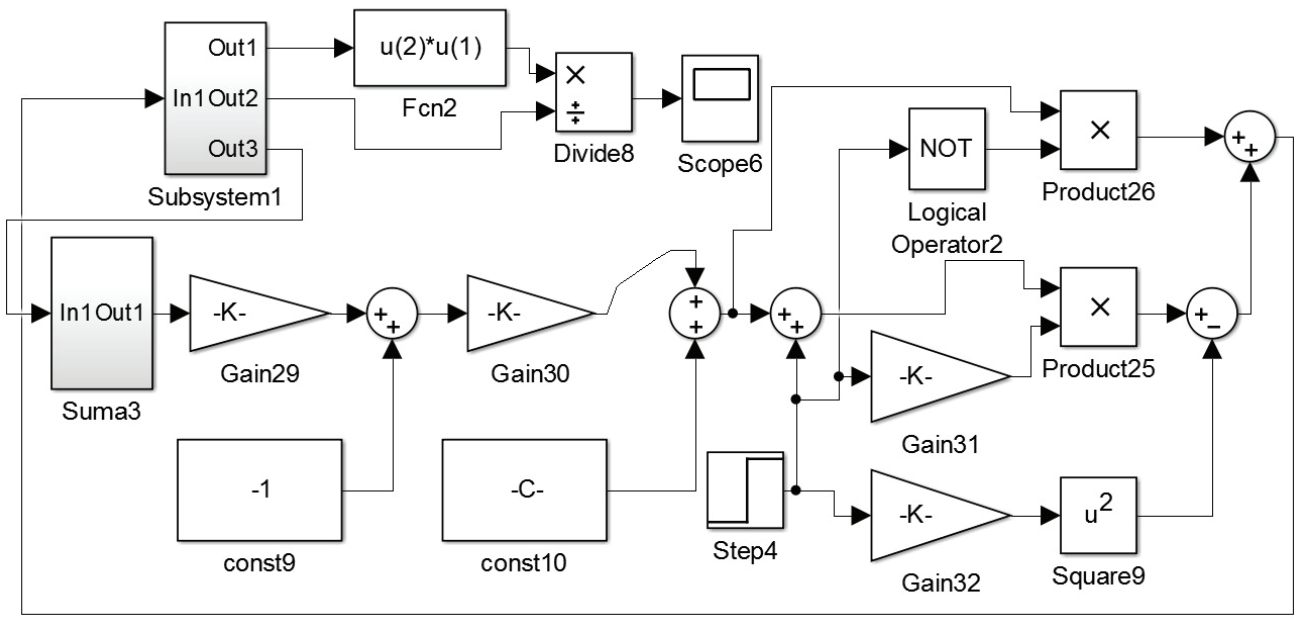

Fig. 5. General minimized simulation model of the electric drive system of the crane taking into account the longitudinal vibrations of the load during its movement

\section{Results}

Fig. 6 shows a graph of the change in time of the dynamic moment acting at the input of the system, obtained using the simulation model shown in Fig. 2. This graph clearly shows the significant dependence of this moment on the variables in time and space of the parameters of this system. Let's recall that the change in time of the parameters is due to the change in time of the reduced moment of inertia of the rotating masses, caused by the change in the radius of the winding drum and the variable mass of both that part of the cable that is wound on the drum, and that which shortens or lengthens between the drum and the load in the process of moving the latter. A change in the parameters of this system in space is due to longitudinal vibrations that arise in the cable during the movement of the load after it is detached from the platform, as well as with any change in the angular velocity of the traction motor.

And Fig. 7 shows a graph of the increase in the angular velocity of rotation of the traction motor shaft after starting to lift the load, obtained using the simulation model shown 
in Fig. 3-5. As it is possible to see that the fluctuations in the angular velocity on this graph are significantly smaller in terms of the fluctuations in the dynamic moment, since the angular velocity is the integral of the dynamic moment related to the reduced moment of inertia, that is, the electric drive system plays in our case the role of a high-frequency filter. But, even despite the filtering, on the graph of the angular velocity, it is possible to see fluctuations within $10 \%$, caused by changes in the parameters of the electric drive system in time and space. For a more visual representation of the oscillations in the same Fig. 7, the lower curve shows the same graph, and the upper one, but on an enlarged scale and only in the range close to the steady velocity.

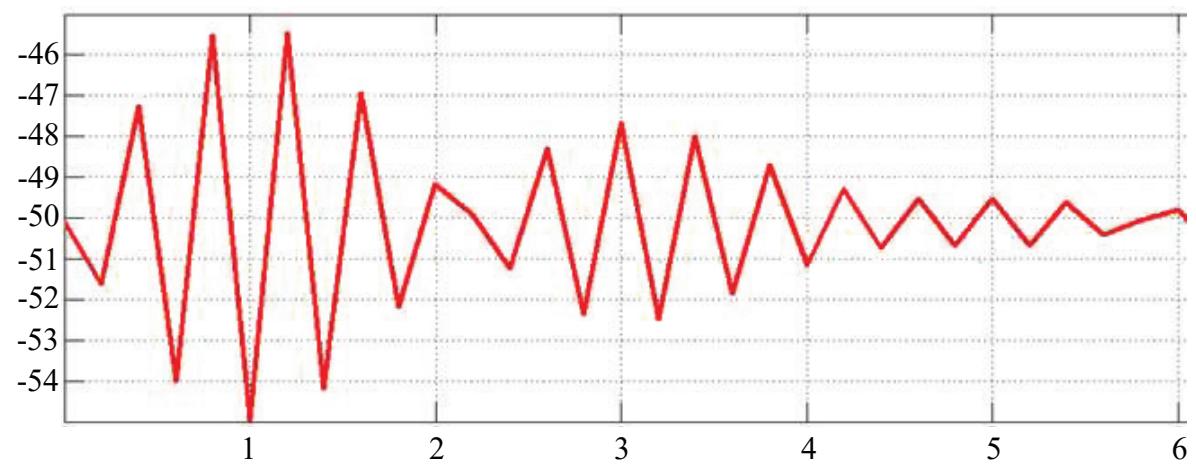

Fig. 6. Results of modeling the change in the dynamic moment of the crane electric drive system
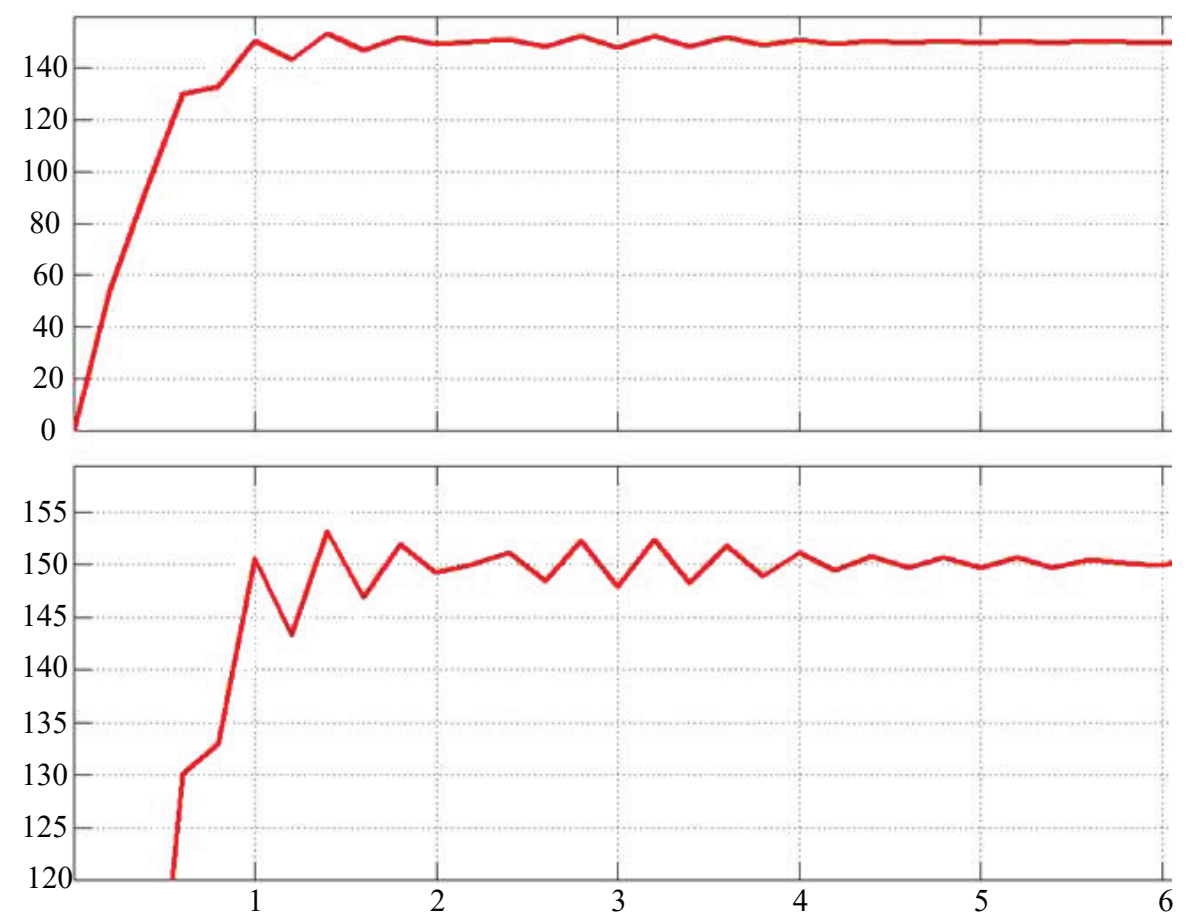

Fig. 7. The results of modeling the change in the angular velocity of the crane mechanism, namely the process of lifting the load, taking into account longitudinal vibrations in the cable

Fig. 8 shows the complete simulation cycle, which also covers the process of decreasing the angular velocity when lifting a load on the final section of the trajectory. From this graph it is easy to see that due to the variable parameters of the system, oscillations arise in the final phase of lifting the load, which can lead to undesirable contacts of the load with the boom or overpass of the crane. 


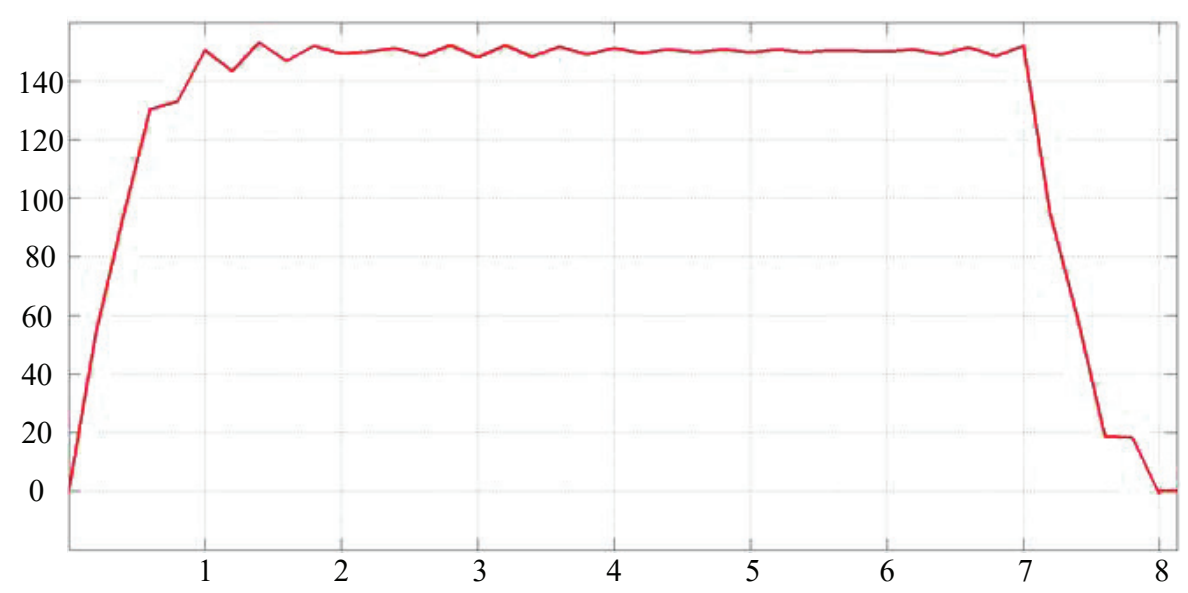

Fig. 8. Graph of the full cycle of changes in the angular velocity of the electric drive of the crane when lifting the load, taking into account longitudinal vibrations in the cable and changes in time of the reduced moment of inertia of the rotating masses

\section{Discussion of research results}

If the graphs of the processes in the electric drive system of the crane, which are shown in Fig. 6-8, and obtained by simulation using the mathematical models synthesized in [8-10], taking into account time and space variables, to compare with the graphs of processes in the electric drive system of the crane with approximately the same characteristics, obtained experimentally by the authors of the work [7], then it is possible to see that they are the same character and only slightly differ in scale, which indicates the adequacy of our mathematical models to real processes that take place in this class of dynamical systems. And at the same time, if there are graphs of processes, obtained by the authors of [7] using mathematical models with stable parameters both in time and space for the two-mass structure of the object, then it is easily possible to make sure that they have a different nature. It is indicates the inadequacy of mathematical models with stable parameters to real processes that take place in this class of dynamical systems.

Despite the fact that the adequacy of the mathematical models of one class of objects with variable parameters in time and space, proposed by the authors of this article in previous works, has been proved by comparing the results of simulation modeling performed in this work with the results of experimental studies of the same class of objects by other authors, the practical value The mathematical models synthesized by the authors can be confirmed only after their use is used to synthesize an automatic control system for objects of this class, which will damp the vibrations that arise in the crane cable due to the influence of changes in time and space of the parameters of the system of its traction electric drive. But the synthesis of such a control system will be carried out already in our next work, which will be a continuation of this work.

\section{Conclusions}

1) Simulation models are synthesized to assess the adequacy of the proposed by the authors of this work in previous publications of mathematical models of one class of linear dynamic systems with variable parameters in time and space, which include systems for lifting and lowering cargo with cranes in the case of taking into account the influence of longitudinal vibrations that arise in the hoisting cable mechanism, and the shift in time of the moment of inertia of the rotating masses reduced to the motor shaft.

2) The simulation in this work is performed in the Simulink graphical software environment of the MATLAB application package, and the results of modeling the dynamics of the electric drive system during acceleration, deceleration and movement at a steady velocity are presented.

3) The way to compare the results obtained on the simulation model with the results of experimental studies of the same class of dynamical systems performed by other authors, the adequacy of the mathematical models synthesized by the authors of this work is proved. 


\section{References}

[1] Grabski, J., Strzałko, J. (2003). Dynamic analysis of the load hoisting process. Journal of theoretical and applied mechanics, 4, 853-872.

[2] Matyja, T., Sładkowski, A. (2007). Modelling of the Lift Crane Vibration Caused by the Lifting Loads. Zdvihaci Zarizeni v Teorii a Praxi 2007. Brno, 98-105.

[3] Pu, H., Xie, X., Liang, G., Yun, X., Pan, H. (2011). Analysis for Dynamic Characteristics in Load-lifting system of the Crane. Procedia Engineering, 16, 586-593. doi: http://doi.org/10.1016/j.proeng.2011.08.1128

[4] Budikov, L. Ia. (1997). Mnogoparametricheskii analiz dinamiki gruzopodemnykh kranov mostovogo tipa. Lugansk: Izd-vo VUGU, 210.

[5] Loveikin, V. S., Chovniuk, Yu. V., Dikteruk, M. H., Pastushenko, S. I. (2004). Modeliuvannia dynamiky mekhanizmiv vantazhopidiomnykh mashyn. Kyiv-Mykolaiv: RVV MDAU, 286.

[6] Vladić, J., Maleńev, P., Ńostakov, R., Brkljač, N. (2008). Dynamic Analysis of the load lifting. Journal of mechanical engineering, 10, 655-661.

[7] Loveikin, V. S., Romasevych, Yu. O., Holdun, V. A., Krushelnytskyi, V. V. (2019). Dynamika ta optymalne keruvannia rukhom mostovykh kraniv. Kyiv: TsP «KOMPRINT», 460.

[8] Mokin, O., Mokin, B., Kryvonis, O. (2017). Synthesis of mathematical models for one class of electromechanical systems with variable parameters. 2017 IEEE First Ukraine Conference on Electrical and Computer Engineering (UKRCON). Kyiv. doi: http://doi.org/10.1109/ukrcon.2017.8100504

[9] Mokin, B. I., Mokin, O. B., Kryvonis, O. M. (2018). Method of Identification of the Mathematical Model of a Single Class of Linear Dynamic Systems with Variable Parameters. Visnyk of Vinnytsia Politechnical Institute, 141 (6), 62-76. doi: http://doi.org/ 10.31649/1997-9266-2018-141-6-62-76

[10] Mokin, B. I., Mokin, O. B., Kryvonis, O. M. (2019). System Approach to the Analysis of the Processes of Moving Cargoes with a Crane. Visnyk of Vinnytsia Politechnical Institute, 144 (3), 21-31. doi: http://doi.org/10.31649/1997-9266-2019-144-3-21-31 